\title{
Potensi Pesawat Udara Nir Awak (PUNA) Alap-Alap Sebagai Teknologi Artificial Intelegence Untuk Pemetaan Lahan Pertanian Produktif
}

\author{
The Potency of UAV as an Artificial Intelligence Technology in Farmland \\ Aerial Mapping
}

Author(s): Yomi Guno ${ }^{(1) *}$; Aditya Inzani Wahdiyat ${ }^{(1)}$; Winda Nawfetrias ${ }^{(1)}$

(1) Badan Pengkajian dan Penerapan Teknologi (BPPT)

* Corresponding author: yomi.guno@bppt.go.id

\begin{abstract}
ABSTRAK
Informasi sumber daya lahan berupa data digital merupakan salah satu data yang menjadi pertimbangan utama pembuat kebijakan dalam menentukan arah pembangunan yang berkelanjutan. Sebagai negara agraris, pelayanan informasi mengenai produktivitas lahan yang cepat dan akurat diperlukan untuk memantau pemanfaatan lahan di Indonesia. Salah satu upaya penyediaan informasi produktivitas lahan adalah melalui implementasi teknologi 4.0 di sektor pertanian. Artificial intelligence (AI) merupakan teknologi utama yang mendukung implementasi teknologi 4.0. Keberadaan AI dinilai sangat potensial dan prospektif untuk memantau lahan pertanian produktif di Indonesia. Pengembangan Pesawat Udara Nir Awak (PUNA) Alap-Alap yang dilengkapi dengan muatan sensor kamera berpotensi diaplikasikan sebagai teknologi AI untuk pemetaan lahan pertanian produktif. Sensor kamera PUNA Alap-Alap berkemampuan 24 Mega Pixel mampu mendapatkan data kondisi lahan pertanian bahkan kondisi tanaman atau vegetasi yang tumbuh di lahan pertanian. Penggunaan sensor kamera mempunyai kelebihan dibandingkan sensor satelit yaitu tidak terkendala tutupan awan, data yang diperoleh realtime dan mempunyai akurasi yang sangat baik. PUNA Alap-Alap menawarkan solusi alternatif untuk melakukan indraja dalam mendukung kegiatan pertanian. Salah satu kelebihan teknologi ini adalah biaya operasional relatif murah dan pengaturan operasi fleksibel sesuai dengan kebutuhan, sehingga operasional PUNA Alap-Alap untuk menghasilkan gambar orthopoto di lahan pertanian produktif cukup efesien. Data akurasi yang dihasilkan oleh PUNA Alap-Alap yaitu Ground Sampling Distance (GSD) 10 $\mathrm{cm} /$ pixel dengan sapuan pengambilan data pemetaan 1700 Ha per jam pada ketinggian terbang 1500 ft. Kelebihan lain adalah PUNA Alap-Alap mampu terbang secara mandiri selama 6 jam tanpa henti, hal ini memungkinkan data pemetaan yang diperoleh mempunyai kualitas dan kuantitas yang baik.
\end{abstract}

\section{Kata Kunci:}

Alap-Alap;

Indraja;

Lahan

pertanian;

PUNA;

Pemetaan;

\section{Keywords:}

Alap-Alap;

Remote

sensing;

Farmland;

$U A V$;

Aerial

Mapping;

\section{ABSTRACT}

The digital information of natural resources is the main consideration for the policies of continuing development. As an agrarian state, Indonesia requires the information of its agricultural productivity in a fast and accurate fashion to observe the usage of its land. One of the efforts to provide such information is to implement the 4.0 technology in the agricultural field. Artificial Intelligence (AI) has the potential prospect to observe the productive agriculture field in Indonesia. The development of Alap-Alap UAV that is equipped with Camera sensor payload has potential applications as AI technology for productive land mapping. The camera sensor of Alap-Alap UAV is capable of 24 Mega Pixel and obtain the data of land, plant, and vegetation at the surface. The application of the camera's sensor has advantages to the satellite's e.g. overcoming the cloud blockage, real-time data gathering, and better accuracy. The Alap-Alap UAV offers alternative solutions for remote sensing in agricultural activities. One of the advantages of this technology is the low-cost of operational expenditure and its flexibility in operation for its purpose thus it is efficient for taking orthophoto in the agricultural land. The accuracy of the Alap-Alap UAV date is $10 \mathrm{~cm} /$ pixel of Ground Sampling Distance (GSD) above $1700 \mathrm{Ha}$ of the area in each hour in $1500 \mathrm{ft}$ of flight altitude. The other advantage is the 6 hours of flight endurance which enables Alap-Alap UAV to produce the preferred quality and quantity of mapping data. 


\section{PENDAHULUAN}

Sampai saat ini, pengumpulan data luas panen terutama padi masih menggunakan metode konvensional yang menggunakan daftar isian Statistik Pertanian (SP) dengan menggunakan metode pengumpulan data luas panen berdasarkan hasil pandangan mata petugas pengumpul data (eye estimate) (Mubekti \& Sumargana, 2016). Meskipun secara praktikal, metode tersebut mudah untuk diterapkan, tetapi penggunaannya masih memiliki kekurangan. Rendahnya akurasi dan waktu pengumpulan data yang cukup lama menjadi beberapa kendala penggunaan metode tersebut.

Teknologi pertanian modern seperti pengindraan jarak jauh (indraja) dapat menjawab kendala tersebut dengan cara mendapatkan data digital lahan seperti luas lahan dengan cepat dan akurat serta diharapkan mampu memprediksi luas area panen dan produktivitasnya. Indraja yang menggunakan citra satelit optik, sering kali terkendala oleh tutupan awan, terutama pada saat musim hujan (Shofiyanti, 2011) .Ketergantungan terhadap data satelit membutuhkan biaya yang besar sehingga mengakibatkan keterlambatan informasi data yang diperoleh.

Perkembangan teknologi pertanian terus merambah ke tahap Artificial intelligence (AI) dengan memanfaatkan teknologi Drone/Pesawat Terbang Tanpa Awak (PTTA)/Pesawat Udara Nir Awak (PUNA) yang dilengkapi dengan sensor kamera beresolusi tinggi bertujuan untuk mendapatkan informasi luas lahan serta tidak menutup kemungkinan diperoleh juga informasi jumlah tanaman yang berada dalam satu lahan secara cepat dan akurat. Selain itu, untuk mendapatkan hasil gambar yang baik, PUNA dapat diterbangkan secara autonomous di bawah awan yang tidak bisa dilakukan oleh foto satelit.

Berdasarkan jenisnya, Drone/PTTA/ PUNA terdapat dua jenis, yaitu multicopter dan fixed wing (Suroso, 2016). Fixed wing memiliki bentuk seperti pesawat terbang konvensional yang dilengkapi dengan sayap. Sedangkan multicopter tidak menggunakan sayap hanya memanfaatkan putaran baling-baling untuk terbang.

Badan Pengkajian dan Penerapan Teknologi (BPPT) merupakan salah satu badan pemerintah yang bergerak dibidang pengembangan teknologi dalam negeri. Salah satu inovasi dari BPPT adalah mengembangkan PUNA Alap-Alap 06D jenis fixed wing dengan konfigurasi double boom-inverted $V$ tail. Pada saat lepas landas, PUNA Alap-Alap memerlukan landasan minimal 50meter untuk take off dan 100meter untuk landing. Pesawat didesain untuk terbang hingga ketinggian maksimum 10,000 kaki dengan berat maksimum pada saat akan terbang (MTOW) $30 \mathrm{~kg}$ serta endurance terbang selama 6 jam tanpa henti (Guno, 2017). Berikut adalah spesifikasi PUNA BPPT 06D ALAP-ALAP DOUBLE BOOM:

$\begin{array}{ll}\text { Wingspan } & : 3 \mathrm{~m} \\ \text { Max Altitude } & : 10,000 \mathrm{ft} / 3048 \mathrm{~m} \\ \text { MTOW } & : 30 \mathrm{Kg} \\ \text { Payload } & : \text { Gimbal Camera } \\ \text { Range } & : 100 \mathrm{Km} \text { (LOS) } \\ \text { Flight Endurance } & : 6 \text { Hours }\end{array}$

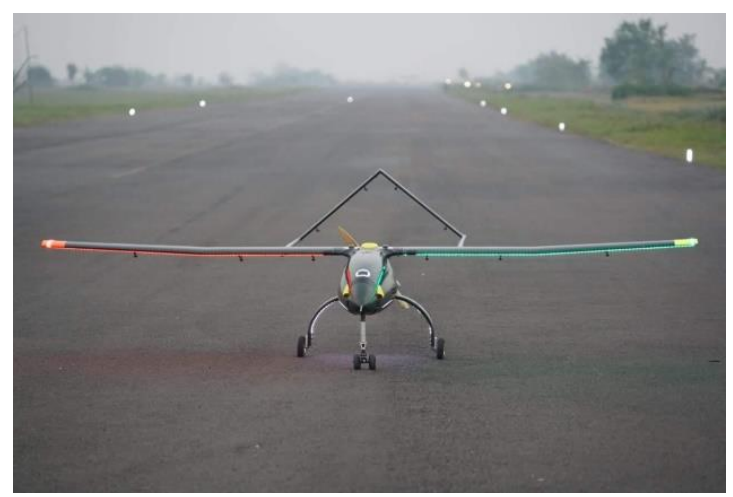

Gambar 1. PUNA Alap-Alap 06D

Figure 1. PUNA Alap-alap 06D 
Dalam menjalankan misinya, PUNA dilengkapi dengan alat atau sistem pengendali terbang otomatis (Auto Pilot dan Autonomous) yang ditransmisikan melalui gelombang radio frekuensi Line of Sight (LOS) dan Non Line of Sight (NLOS) (Zanmiller, 2013), peralatan navigasi yang sangat presisi dengan Differential Global Positioning System (DGPS) serta peralatan kamera beresolusi tinggi.

Beberapa keuntungan dan keterbatasan penggunaan PUNA AlapAlap, antara lain:

1. Operasi dapat dilakukan dimana saja, dan dapat dilakukan secara berulang setiap saat untuk pemantauan lahan, sehingga dapat diperoleh gambar yang real time.

2. Mampu terbang rendah dibawah awan, sehingga dapat menghasilkan gambar dengan resolusi tinggi.

3. Tanpa diperlukan pilot di dalam pesawat, sehingga relatif aman.

Akan tetapi PUNA Alap-Alap juga memiliki keterbatasan, antara lain:

1. Biaya investasi awal relatif mahal (tergantung pada ukuran dan kompleksitas PUNA).

2. Persyaratan perizinan terbang, sertifikasi khusus untuk pilot serta penggunaan wilayah udara yang sangat ketat.

\section{METODOLOGI}

Data yang diambil untuk melakukan kegiatan pemetaan lahan pertanian merupakan data foto udara berupa orthophoto. Teknik orthophoto merupakan sebuah foto udara yang telah dikoreksi geometris (orthorectified) sedemikian rupa sehingga skala foto itu adalah seragam (Wolf et al., 2013).

Secara umum Teknik pengambilan foto udara terdapat 3 cara pengambilan gambar yaitu:

1. Vertical Aerial Photo

2. Low Oblique Photo

3. High Oblique Photo

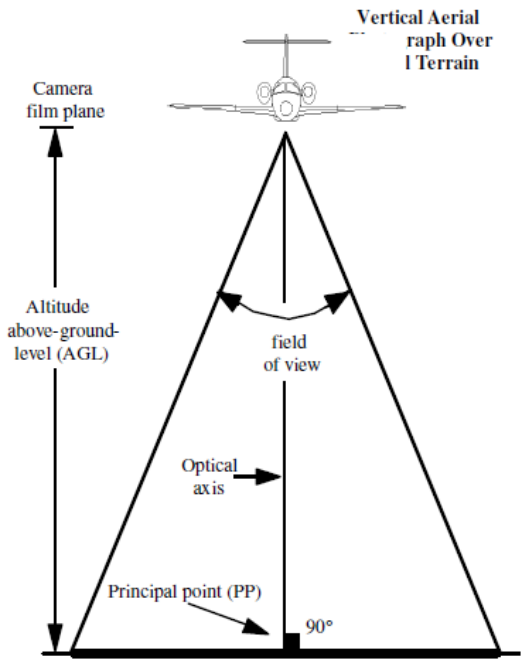

Gambar 2. Vertical Aerial Photo Figure 2. Vertical Aerial Photo

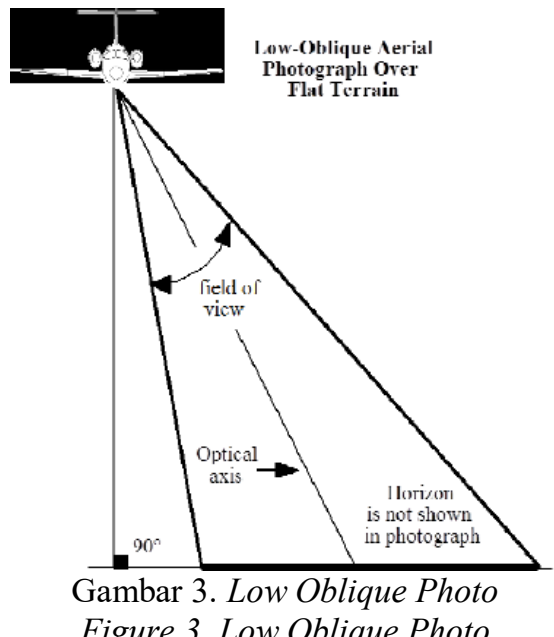

Figure 3. Low Oblique Photo

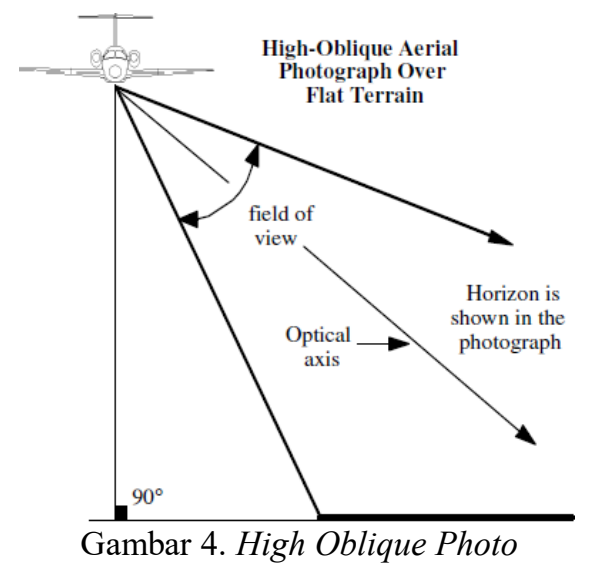

Figure 4. High Oblique Photo 
Pengambilan foto udara secara vertical aerial photo mempunyai kelebihan dibandingkan dengan cara pengambilan foto secara oblique yaitu:

a) Skala pada setiap bagian foto lebih seragam.

b) Perkiraan arah dapat ditentukan seperti penentuan arah pada peta.

c) Dalam batas tertentu, dapat dipakai sebagai substitusi peta.

Sedangkan foto udara menggunakan metode oblique juga mempunyai beberapa kelebihan antara lain:

a) Luas area yang difoto lebih besar karena sudut pengambilan tidak tegak lurus.

b) Untuk daerah yang sering tertutup oleh awan, masih ada kemungkinan menembus celah-celah awan bila dilakukan pemotretan condong.

c) Mendapatkan model 3D dari suatu objek.

Teknik pengambilan foto pada saat melakukan pemantauan lahan pertanian yang diterapkan di PUNA Alap-Alap menggunakan vertical aerial photo karena ukuran geometrinya lebih teliti dan cara pengukurannya juga lebih mudah. Selain itu, parameter intrinsik yang berkaitan dengan parameter kamera dalam melakukan pemetaan serta parameter ekstrinsik yang merupakan kondisi pesawat saat mengambil foto pemetaan dalam hal ini ketinggian dari pesawat perlu diperhatikan agar mendapatkan hasil foto udara yang teliti dan akurat.

Sensor kamera yang digunakan PUNA Alap-Alap dalam melakukan operasi pemetaan lahan menggunakan kamera mirrorless SONY a6000 24.3 MP dengan Ground Sampling Distance (GSD) yang sangat baik yaitu $10 \mathrm{~cm} /$ pixel pada ketinggian terbang di $1500 \mathrm{ft}$. Nilai GSD dapat dihitung menggunakan persamaan berikut:

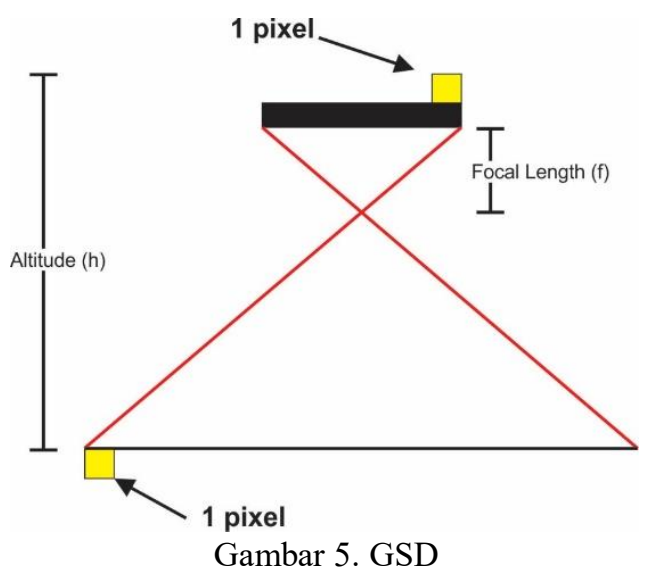

Figure 5. Ground Sampling Distance (GSD)

$$
\mathrm{GSD}=\frac{\text { Pixel Size } \cdot \text { Altitude }}{\text { Focal Length }}
$$

Ground sampling distance didefinisikan sebagai besar satu pixel pada bumi (Bosak, 2013). Nilai GSD (cm/pixel) akan menunjukan kualitas foto udara yang diambil. Untuk mendapatkan hasil foto yang tidak terputus, pada saat melakukan pengambilan foto udara PUNA Alap-Alap menggunakan metode overlap dan sidelap sebesar $60 \%$, yang di defenisikan $60 \%$ gambar di foto pertama akan terfoto lagi di foto kedua sehingga data gambar saling berkaitan dengan gambar sebelumnya.

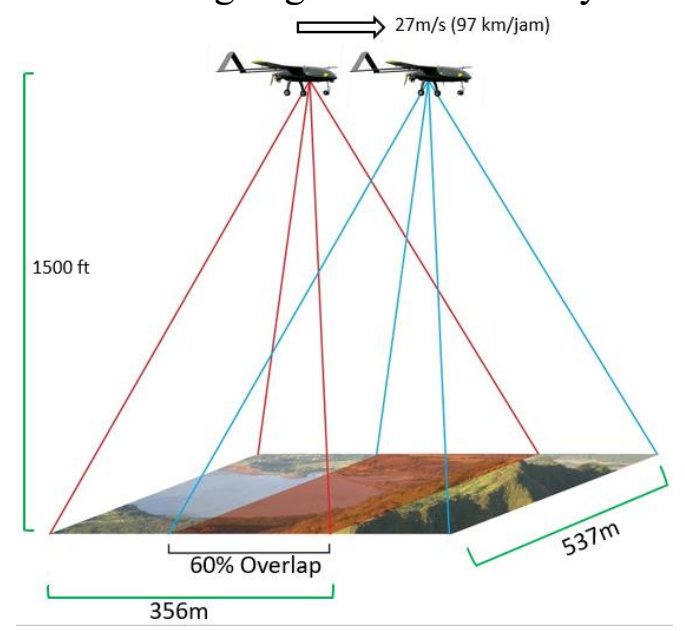

Gambar 6. Overlap dan Sidelap 60\% Figure 6. Overlap and Sidelap 60\% 
Dengan adanya metode overlap dan sidelap, semua area akan terfoto tidak hanya sekali. Sehingga proses photogrammetry akan menjadi lebih akurat (Luhmann, 2010). Selanjutnya setelah proses pengambilan foto selesai, dilakukan proses digital photogrammetry dengan cara mencari titik ikat dari setiap foto untuk membentuk objek 3D dan mengubah foto menjadi orthophoto (Kiessling, 2013).

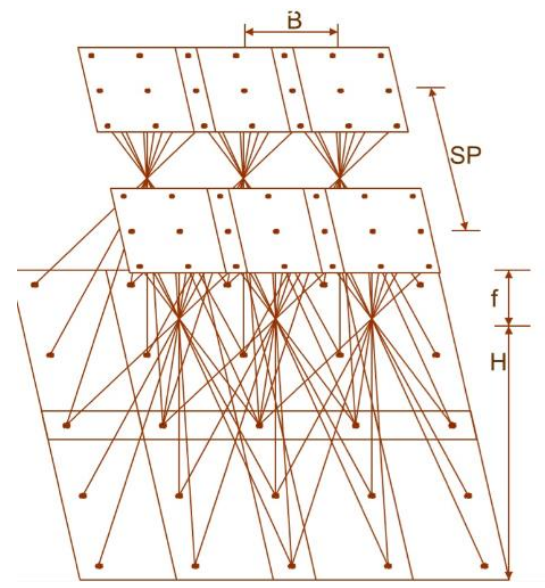

Gambar 7. Titik ikat Photogrametry

Figure 7. The photogrammetry bond point

\section{HASIL DAN PEMBAHASAN}

Salah satu penerapan teknologi PUNA Alap-Alap dibidang pertanian diterapkan pada kegiatan Uji Akurasi Metode Kerangka Sample Area (KSA) lahan padi di kecamatan Bongas, Kabupaten Cirebon. PUNA Alap-Alap difungsikan untuk mengambil data foto udara lahan padi secara cepat dan hasil dari kegiatan tersebut berupa foto lahan dalam bentuk orthopoto. Total luas area lahan padi yang dipetakan seluas $\pm 4200 \mathrm{Ha}$ dengan waktu pemetaan foto udara selama 3 jam 5 menit.

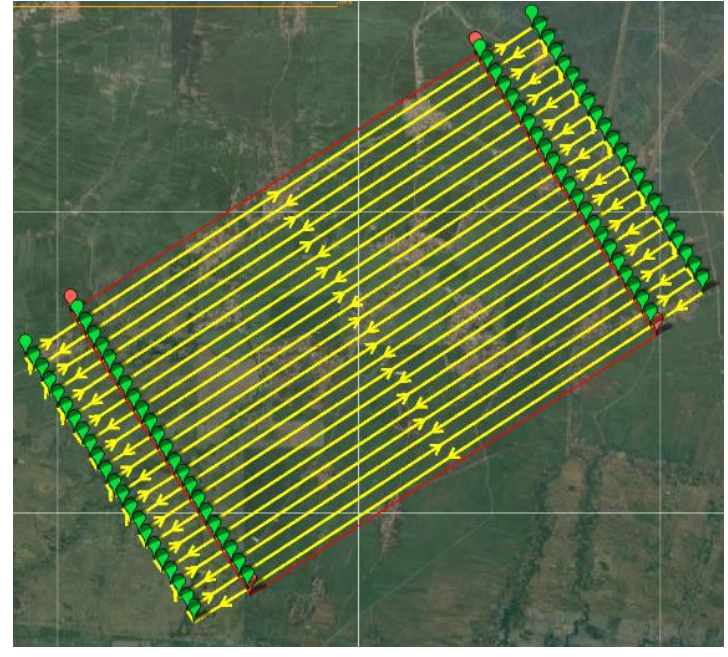

Gambar 8. Rute Terbang Pengambilan Foto Udara PUNA Alap-Alap di Lahan Padi Bongas

Figure 8. Fly route of PUNA Alap-alap for photographs taking on Bongas rice field

Ketinggian terbang PUNA AlapAlap pada saat melakukan misi pemetaan foto udara berada di ketinggian 1500 $\mathrm{ft} / \pm 500 \mathrm{~m}$ dengan kecepatan rata-rata 27 $\mathrm{m} / \mathrm{s}$ serta endurance terbang selama 6 jam tanpa henti. Pesawat PUNA Alap-Alap diterbangkan dari Bandara Cakrabhuwana Cirebon dengan menempuh perjalanan pergi (Takeoff) dan pulang (Landing) sejauh $165.6 \mathrm{~km}$ dengan waktu terbang selama 2 jam diluar misi pemetaan lahan padi. Jalur terbang PUNA Alap-Alap yang dizinkan dari AirNav harus melewati rute WICD (Cirebon Airport) $\rightarrow$ CA NDB/Gapit -> JAMBE $->$ IMU $\quad->$ BONGA dikarenakan sudah beroperasinya Bandara Kertajati. 


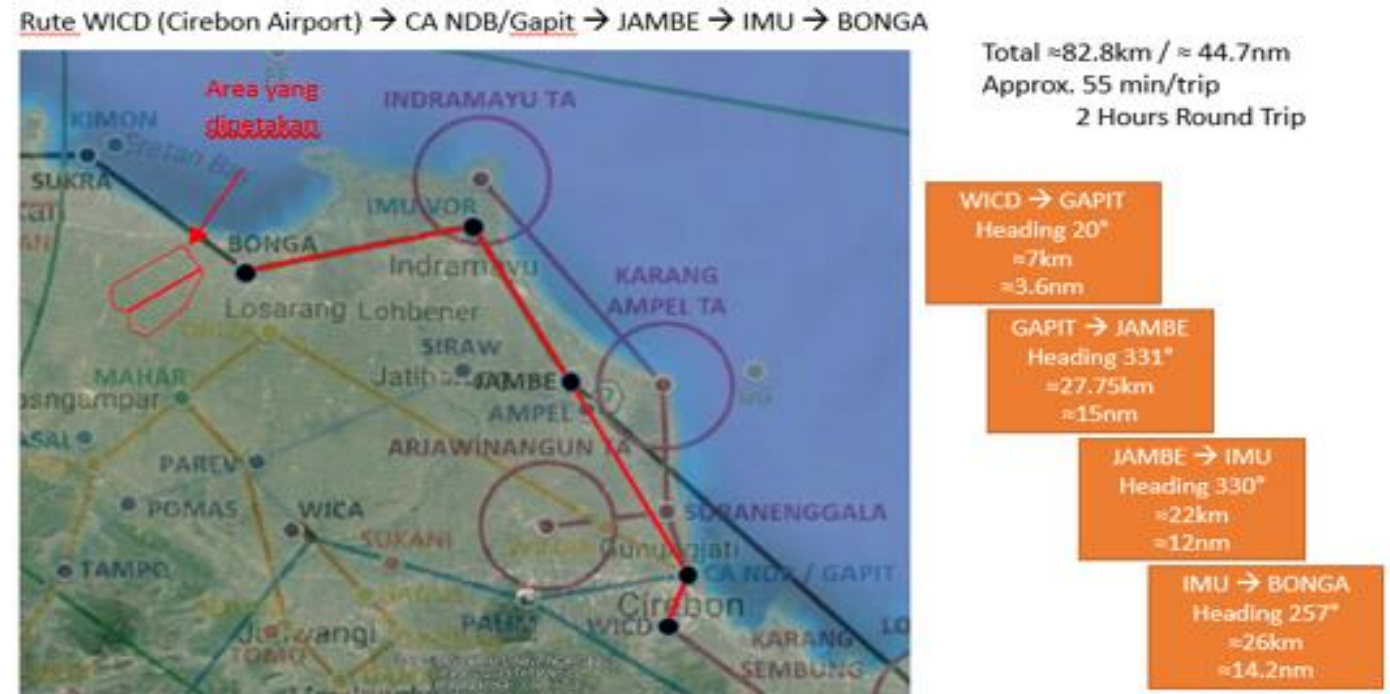

Gambar 9. Jalur Terbang PUNA Alap-Alap dari Bandara Cakrabhuwana Cirebon Figure 9. PUNA Alap-Alap Flyway from Cakrabhuwana Airport Cirebon

PUNA Alap-Alap terbang sesuai dengan rute terbang yang telah ditentukan secara autopilot dan autonomous. Area yang dipetakan berdasarkan dari hasil foto udara berupa raw data yang selanjutnya dilakukan pengolahan secara photogrammetry dengan menggunakan software Agisoft PhotoScan. Berikut hasil dari pengolahan software Agisoft PhotoScan untuk skala $500 \mathrm{~m}$ dan skala 60 m.

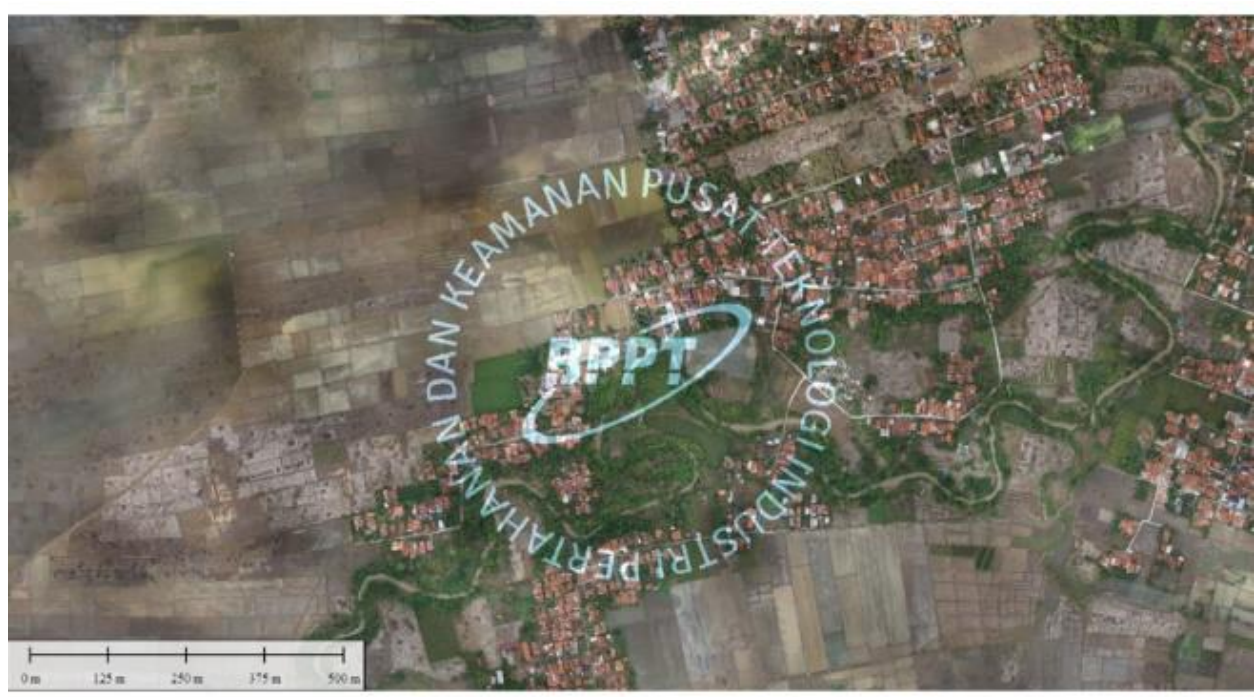

Gambar 10. Foto Udara Pemetaan Lahan skala $500 \mathrm{~m}$

Figure 10. Aerial Photo of Land Mapping at $500 \mathrm{~m}$ scale 


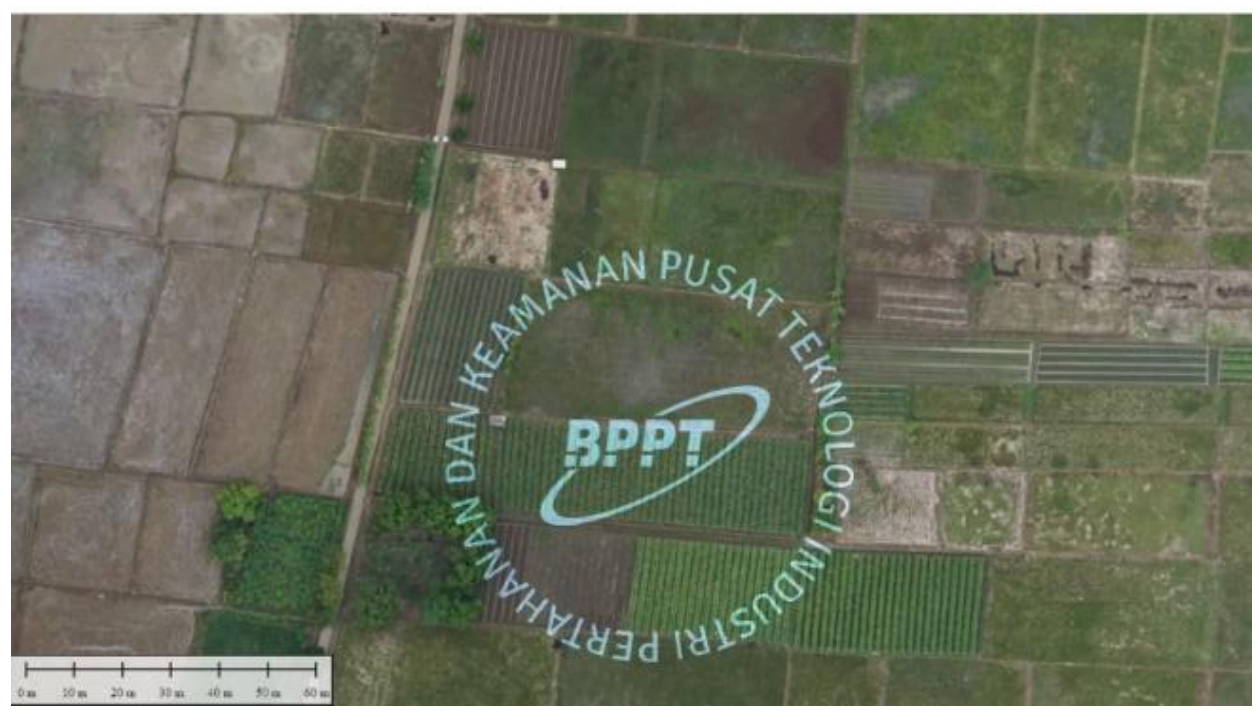

Gambar 11. Foto Udara Pemetaan Lahan skala $60 \mathrm{~m}$ Figure 11. Aerial Photo of Land Mapping at $60 \mathrm{~m}$ scale

\section{KESIMPULAN}

Pesawat Udara Nir Awak (PUNA) Alap-Alap merupakan piranti yang sangat berguna untuk aplikasi pertanian dalam hal pemetaan lahan secara cepat sehingga mampu mendukung kegiatan pengambilan data lahan Uji Akurasi Metode Kerangka Sample Area (KSA) dibandingkan dengan menggunakan metode eye estimate.

Walaupun masih terdapat kekurangannya, kemudahan dalam pengoperasiannya, fleksibilitas waktu dan mudah dalam melakukan misi pemetaan dianggap sebagai salah satu kelebihan dari penggunaan PUNA Alap-Alap jika dibandingkan menggunakan foto satelit. Selain itu penggunaan PUNA Alap-Alap juga minim risiko karena tidak adanya pilot di dalam pesawat. Pesawat akan dikendalikan secara Auto Pilot dan Autonomous dari Ground Control Station.

Kelebihan PUNA Alap-Alap dibandingkan dengan PTTA/Drone lainnya adalah mampu terbang tanpa henti selama 6 jam dengan sapuan pengambilan data pemetaan $1700 \mathrm{Ha}$ per jam pada ketinggian terbang $1500 \mathrm{ft}$. Citra yang dihasilkan cukup baik dan beresolusi tinggi dengan Ground Sampling Distance (GSD) 10 $\mathrm{cm} /$ pixel. sehingga memiliki potensi besar untuk identifikasi dan pemantauan lahan pertanian berskala besar.

Penelitian dan pengkajian masih perlu terus dilakukan untuk mengembangkan teknik ini secara operasional agar citra atau foto dapat diolah menjadi informasi pertanian yang berguna baik untuk operasional di lapangan maupun untuk dasar acuan bagi pengambil kebijakan.

\section{DAFTAR PUSTAKA}

Bosak, K. (2013). Secrets of UAV 割 Photomapping. http://s3.amazonaws .com/DroneMapper_US/documentat ion/pteryx-mapping-secrets.pdf

Guno, Y. (2017). Pemanfaatan Pesawat 期 Udara Nir Awak (PUNA) Untuk Pemantauan Mitigasi Bencana Gunung Berapi. Majalah Ilmiah Pengkajian Industri, 11(3), 231-238. https://doi.org/10.29122/mipi.v11i3. 2486

Kiessling, K. (2013). Getting started with El Agisoft PhotoScan. http:// www.atelier3d.levillage.org/IMG/pd 
f/Getting_started_with_Agisoft_Pho toscan.pdf

Luhmann, T. (2010). Close Range 钢 Photogrammetry for Industrial Applications. ISPRS Journal of Photogrammetry and Remote Sensing, 65(6), 558-569. https://doi.org/10.1016/j.isprsjprs.20 10.06 .003

Mubekti, \& Sumargana, L. (2016). 钢 Pendekatan Kerangka Sampel Area untuk Estimasi dan Peramalan Produksi Padi. Jurnal Pangan, 25(2), 71-72.

Shofiyanti, R. (2011). Teknologi Pesawat 钢 Tanpa Awak Untuk Pemetaan dan Pemantauan Tanaman dan Lahan Pertanian. Informatika Pertanian, 20(2), 58-64.

Suroso, I. (2016). Peran Drone/Unmanned 镀 Aerial Vehicle ( UAV ) Buatan STTKD dalam Dunia Penerbangan. Pengembangan Kebijakan Dan Regulasi Penerbangan Dan Antariksa: Problema Dan Tantangan, 104-112. https://doi.org/10.30536/p.sinaskpa.i .12

Wolf, P. R., DeWitt, B. A., \& Wilkinson, EQ B. (2013). Elements of Photogrammetry with Applications in GIS (4th ed.). McGraw-Hill Education.

Zanmiller, M. (2013). Piccolo Software-in尌 Loop (SiL) Setup Guide. http://www.cloudcaptech.com/produ cts/detail/piccolo-SL1 